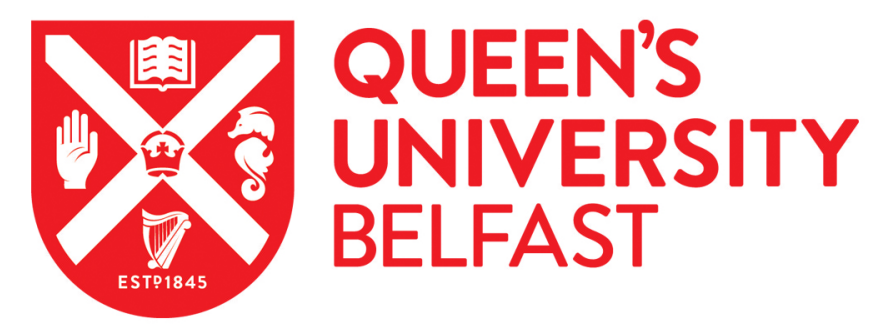

\title{
Exploring public awareness and perceptions of palliative care: a qualitative study
}

Mcllfatrick, S., Noble, H., McCorry, N. K., Roulston, A., Hasson, F., McLaughlin, D., Johnston, G., Rutherford, L., Payne, C., Kernohan, G., Kelly, S., \& Craig, A. (2014). Exploring public awareness and perceptions of palliative care: a qualitative study. Palliative Medicine, 28(3), 273-280. https://doi.org/10.1177/0269216313502372

Published in:

Palliative Medicine

Document Version:

Peer reviewed version

Queen's University Belfast - Research Portal:

Link to publication record in Queen's University Belfast Research Portal

Publisher rights

Copyright 2013 The Authors, published by Sage

\section{General rights}

Copyright for the publications made accessible via the Queen's University Belfast Research Portal is retained by the author(s) and / or other copyright owners and it is a condition of accessing these publications that users recognise and abide by the legal requirements associated with these rights.

Take down policy

The Research Portal is Queen's institutional repository that provides access to Queen's research output. Every effort has been made to ensure that content in the Research Portal does not infringe any person's rights, or applicable UK laws. If you discover content in the Research Portal that you believe breaches copyright or violates any law, please contact openaccess@qub.ac.uk. 
Exploring public awareness and perceptions of palliative care: a qualitative study

Sonja Mcllfatrick School of Nursing, University of Ulster, UK; All Ireland Institute of Hospice and Palliative Care (AllHPC), Ireland; Palliative Care Forum for Northern Ireland, UK

Helen Noble School of Nursing and Midwifery, Queen's University Belfast, UK

Noleen K McCorry Marie Curie Hospice Belfast, Marie Curie Cancer Care, UK

Audrey Roulston School of Sociology, Social Policy, and Social Work, Queen's University Belfast, UK

Felicity Hasson School of Nursing, University of Ulster, UK

Dorry McLaughlin School of Nursing and Midwifery, Queen's University

Belfast, UK

Gail Johnston Health and Social Care Research and Development Division, Public Health Agency Northern Ireland, UK

Lesley Rutherford School of Nursing and Midwifery, Queens University Belfast, UK; Marie Curie Hospice Belfast, Marie Curie Cancer Care, UK Cathy Payne School of Health Sciences, University of Ulster, UK

George Kernohan School of Nursing, University of Ulster, UK Sheila Kelly Patient and Client Council Northern Ireland Avril Craig Patient and Client Council Northern Ireland 


\section{Corresponding Author:}

Sonja Mcllfatrick, School of Nursing, University of Ulster, Jordanstown

Campus, Shore Road, Newtownabbey, BT37 OQB, UK.

Email: sj.mcilfatrick@ulster.ac.uk 


\section{Abstract}

Background: Research suggests that the public appear to be confused about the meaning of palliative care. Given the aging population and associated increase in the number of patients requiring palliative care it is vital to explore the public's understanding of this concept. Health promoting palliative care seeks to translate hospice and palliative care ideals into broader public health practice.

Aim: To explore public perceptions of palliative care and identify strategies to raise awareness.

Design: An exploratory qualitative approach.

Participants: Semi structured telephone interviews were undertaken $(n=50)$ with members of the public who volunteered to participate in the study. The interviews focused on knowledge and perceptions of palliative care; expectations of palliative care services and the identification of strategies to raise public awareness of palliative care. The interviews were audio recorded and content analysed.

Results: Most participants had a general knowledge of palliative care, largely influenced by their own personal experience. They identified that palliative care was about caring for people who were dying and maintaining comfort in the last days of life. Participant's expectations of services included: holistic support, symptom management; good communication; and practical support to enable choice and carer support. A key aspect identified for promoting palliative care was the development of understanding and use of the term itself and targeted educational strategies. 
Conclusions: Experience of palliative care generates understanding in the general public who also have ideas for increasing knowledge and awareness. The findings can inform policy makers about strategies to raise public awareness of palliative care.

Word count 250

\section{Keywords:}

Palliative care, public awareness, public health, telephone interviews, health promoting palliative care 


\section{Introduction}

In recent years there has been an increased recognition of a global public health need for palliative care. ${ }^{1}$ Palliative care aims to improves the quality of life of patients and families facing life-threatening illness . ${ }^{2}$ Public health palliative care or health promoting palliative care is concerned with building public policies that support dying, death, loss and grief, create supportive environments, strengthen community action and allow people to develop personal skills in these area $^{3}$.There are, however, numerous challenges to developing a public health approach, one being the low level of public awareness of palliative care, highlighted by several international surveys. ${ }^{4-7}$ Research continues to suggest that the public is 'death denying' and that conversation about death and dying remains largely 'taboo'. 8-12 Public confusion about end of life terminology is unsurprising when set against the background of debate amongst researchers, practitioners and policy makers about the scope, definitions, goals and approaches of palliative care ${ }^{13-14}$ and the changing historical definitions of the term. ${ }^{2}$ In the UK this situation has been further complicated by recent negative media attention ${ }^{15.16}$ about the Liverpool Care Pathway for Dying Patients (LCP) (an internationally recognised best practice model for caring for people in the final days of life). Whilst the LCP is well supported by practitioners (with $90 \%$ of doctors agreeing in a recent study that they would be happy to be placed on the pathway if they were dying ${ }^{17}$ ) confusion has been generated publically about its role in palliative and end of life care at a time when misunderstandings about the aims of palliative care already exist. Negative perceptions about death and dying may manifest as fears and anxieties about the dying process, fears over lack of control at end-of-life, lack of openness between close family members when a person is dying, and behaviours associated with accessing palliative and end of life care services. ${ }^{18-22}$

Nevertheless, public opinion surveys in both the UK and Ireland have shown that the public perceives there to be insufficient conversation about death and dying in the community,23-24 and the majority would welcome discussions with clinicians in advance about end of life issues.9,25 Modification of public 
perceptions of palliative care is central to improving knowledge of and access to services, empowering individuals, and involving communities in palliative and end of life care. However, it is recognised that public attitudes to palliative and end of life care are complex and equivocal ${ }^{21}$ and that efforts to improve public awareness need to take account of cultural characteristics, ${ }^{11,21,26-27}$ demographics, ${ }^{20,25,26}$ ethnicity ${ }^{20}$ and social structure, including religious affiliation. 26,28. Detailed and comprehensive knowledge of public views towards palliative care is required in order to target education and policy campaigns, manage future needs, expectations and resourcing of end of life care. The current study aimed to explore public perceptions towards palliative care in a region in the UK.

The aim of this study was to explore public perceptions towards palliative care. In developing the objectives of the study the principles of a public health palliative care approach were considered. Therefore, the objectives of the study were:

1. To identify the public's understanding and perceptions of palliative care

2. To explore factors that contribute to the public's knowledge and expectations of palliative care services

3. To identify what actions and strategies the public consider might enhance public awareness and understanding of palliative care

\section{Methodology}

\section{Research Design}

A qualitative exploratory design was used, utilising semi-structured telephone interviews. This paper followed the COREQ guidelines for reporting qualitative research.

\section{Participants and recruitment}

Participants were members of an independent membership scheme, which was established to provide an independent voice for patients, clients, carers 
and communities on health and social care issues in Northern Ireland. Members of the scheme's database who had previously taken part in a quantitative phase of the study $(n=600)$ were sent a postcard asking them to indicate their interest to participate in the telephone interviews. The inclusion criteria were: age over 18 years and willingness to provide written consent. The exclusion criteria were: diagnosed with an advanced progressive disease or suffered bereavement within the last six months. Individuals who returned a postcard were posted a research information pack outlining the nature and purpose of the project, an information sheet (detailing participants' rights, level of risk and inclusion criteria), and a consent form (with stamped address envelope). Telephone interviews were conducted with those individuals who returned a completed consent form (indicating consent to interview and to audio-recording of the interview), and who met the inclusion criteria (which was screened by the interviewer prior to interview) $(n=50)$. It was felt this would be a sufficient number to reach data saturation.

\section{Data collection}

Data collection took place between September and December 2012. In order to guide a consistent flow to the telephone interview discussion a semistructured interview guide was developed (See Table 1). Questions were designed to be broad including both closed and open-ended to enable participants to convey their views. The interview schedule was based upon topics generated from a review of the literature. The format for the interviews was structured into three main sections. Section one examined knowledge and perceptions of palliative care; section two explored expectations for palliative care service provision and section three explored strategies to 
promote public awareness of palliative care. The telephone interviews lasted between 25 and 40 minutes and each discussion was audio-taped and supplemented by field notes. No participants' names were recorded on the audio recording; instead each participant was allocated a unique code that was only identifiable to the researcher. Written consent was secured from each interviewee for participating and audio recording prior to each telephone interview

Although using telephone interviews did not allow for observation of nonverbal cues when discussing a potentially sensitive topic, the need for sensitivity and awareness was acknowledged. This use of telephone interviews has been used previously in palliative care research and has been commended as a data gathering technique that is least burdensome for respondents ${ }^{29}$. The interviews were undertaken by six members of the research team who were experts in palliative care and registered health care professionals. All interviews were fully transcribed. Ethical approval for the study was obtained from the University Ethics Committee. Participants were provided with details for further information and telephone advice support lines.

\section{Please insert table 1 here.}

\section{Data analysis}

Detailed thematic content analysis of the interview material was undertaken using Miles and Hubermans'30 framework. Data were analysed iteratively. Members of the research team who had conducted the interviews initially analysed interviews separately to identify themes. Subsequently the research 
team met to compare notes and authenticate key themes and sub-themes. Identified subthemes were considered in relation to relevant literature. Initial differences between the researchers were resolved through discussion. Themes were verified to determine whether participants' experiences had been adequately and accurately represented.

The systematic approach employed helped to increase the truthfulness and consistency of the findings. The developed coding frame was grounded in the data rather than decided a priori ${ }^{30}$. Throughout the study reflective notes of the data collection process were maintained by each researcher and personal opinions and emotional responses were discussed during data analysis.

\section{Findings}

Themes are presented under each of the three sections of the interview schedule: general knowledge and perceptions of palliative care; expectations of palliative care services and methods of enhancing awareness and understanding.

$$
\text { Please insert table } 2 \text { here }
$$

\section{General knowledge and perceptions of palliative care}

Knowledge of palliative care varied according to respondents' personal and professional experiences. At one end of the spectrum, respondents had no former knowledge only learned about palliative care when invited to participate in this study.

'Well, I honestly didn't know what it was until I read that it was to do with dying. I hadn't got a clue...I've honestly never heard of it' (ID50). 
It was suggested that people do not know about palliative care services and that such knowledge is acquired when 'you are in the situation of needing care' (ID2, former hospital patient) or in a caring role:

'What I would say is it would probably be important for people who maybe had a relative, a very close relative maybe nearing the end of time' (ID 49).

Although some had heard of 'palliative care' they did not understand it, compared to others with firsthand experiences of being diagnosed with cancer or caring for relatives. Health professionals or volunteers showed greatest insight with one describing it as 'living until you die' (ID10, hospice volunteer) and another suggesting 'it's about end of life treatment' (ID1, District Nurse). The objectives were emphasised by another professional:

'I would look upon [Palliative care] as somebody who had a terminal or life-limiting illness requiring care that is not necessarily, well it's not going to be a cure, but something that would help them to live with and cope with the situation....and it would be by specialist staff who are particularly trained in that field, who had expertise over and above the normal run of the mill GP or hospital doctor' (ID56, female, Registered Nurse).

There was acknowledgement that people needing palliative care services have an incurable illness impacting on their life expectancy, and that care is best delivered by trained specialists. 


\section{Shifting trends in palliative care.}

Most respondents assumed that palliative care focuses on cancer with some awareness of the recent inclusion of other life-limiting illnesses (Motor Neurone's Disease, Multiple Sclerosis, Parkinson's Disease, dementia and heart or renal failure).

'My interpretation of palliative care is [...] I generally would have associated it with cancer but I'm now aware that it goes out into other illnesses as well' (ID44).

This knowledge generally appeared to have been obtained from professional or personal exposure to patients being care for by local hospices.

'Palliative care used to focus on cancer but local hospices are now taking people with other life-limiting disease such as MND, which could be developed further to include heart or renal failure' (ID20, retired nurse).

Some knowledge evolved from recent media exposure through TV or radio programmes about end of life care, euthanasia and the Liverpool Care Pathway.

Accessibility of information on palliative care. Findings revealed the absence of a single focal point for accessing information. Although doctors or the health centre were most popular, some had reservations. 
'Doctors are always so busy...I would never dream of going into ask the doctor for advice...there are so many people...but maybe someone at reception would help...in saying that, I don't know that I would go and ask if there was a queue behind me' (ID34).

Others preferred the convenience and privacy of home internet resources.

Location of palliative care services. When respondents were asked where they thought palliative care takes place, most suggested hospital, hospice, nursing home, or home.

'I assume home, hospital and hospice...but it is more at home, but I don't know why that is, maybe that is a common misconception... but I think the term palliative care would make me think about the home environment' (ID15 ).

Responses included expectations with a strong preference towards home, offering care within their 'own environment' (ID15) and where it was assumed 'most people would like to be cared for' (ID1, District Nurse). One respondent emphasised how a home death benefitted his wife and family:

'My wife died of cancer and she wanted to stay at home. Marie Curie nurses were coming in and my daughter and me and friends, we 
looked after her. It's a much needed thing palliative care, for patients staying at home, it helps the family' (ID4, bereaved carer).

Based on personal experiences, the least preferred options were a hospital or nursing home. Some shared negative encounters with nursing homes, with one describing care as 'atrocious' (ID11) and others perceiving hospital care as 'uncaring' (ID3) and 'abysmal' (ID37).

'The best place for palliative care to take place is in the home...if it is at all possible. There is no doubt there are hospices, hospitals, and no doubt a form of palliative care in nursing homes. [...] My experience is that it is best at home. The next place is hospices. Hospitals are totally uncaring and it shouldn't happen there' (ID3).

This respondent indicated a strong preference for palliative care at home, suggesting that exposure to services, directly or indirectly, may influence public preferences.

\section{Expectations for palliative care services}

What do the public expect for patients? Although there was recognition that 'it is not always possible to relieve pain 100\%' and that 'sometimes we want our loved ones to live forever' (ID20, retired nurse), findings revealed the importance of ensuring that patients are comfortable, suffering is alleviated and dignity is promoted in the last days of life. 
'It's looking after people who are dying and making their death as easy and comfortable as possible' (ID7).

One respondent (ID10) emphasised the importance of 'helping someone to be comfortable' which was based on memories of her sibling 'screaming in agony in hospital...as she never saw a palliative care nurse'. Others shared positive experiences of specialist palliative care at home or hospice.

Holistic services expected from professionals. Although findings suggest a focus on physical care, the need to consistently address psychological, spiritual, emotional and practical needs was highlighted. One respondent expressed disappointment with her experience of services.

'I was disappointed by the specialist palliative care nurses, they seemed to be more focused on symptom relief versus psychological help, psychological side needs to be a higher priority for patients and families' (ID20, retired nurse).

There was also an expectation that palliative care should offer 'softer' aspects of care such as 'easing of the burden, a helping hand, comfort for the patient' (ID24), which was reflected by another respondent.

'If I was terminally ill and approaching death I would like to think that I had someone by my side who would understand what I was experiencing and going through and help me through it until closure. 
Someone who would be skilled in the taking care of someone who was dying' (ID36).

Findings revealed the importance of professional training, treating individuals respectfully and communicating difficult information competently. Health care professionals may 'offer lay people insight into palliative care and dying' (ID20, retired nurse). However, communication should be sympathetic and compassionate rather than 'coming across as being very sharp' (ID11, retired doctor). Some benefits of open communication are illustrated below:

'My wife had very progressive ovarian cancer and was told that she only had days to live...the palliative care team come and seen me the next day and told me... It was an absolute God send ... We had six or seven days where we were able to talk things over, between ourselves...so those were very precious days to me.' (ID6)

This illustrates the importance of people being aware of the preciousness of time and facilitating open communication so that patients can 'tie up their life and issues' (ID34). Although ethical and practical difficulties may arise when patients do not know their diagnosis or 'families refuse to have them told' (ID60), it was acknowledged that not everyone wishes to engage in palliative care (ID39) and decision-making should be respected. 


\section{Support expected for family carers}

Caring for a dying relative is a 'very stressful time for families' (ID3) and they cannot always provide the hands-on care, despite expectations (ID20, retired nurse). The perceived 'burden' that caring places on relatives was temporarily alleviated through respite, as it enabled carers to live a 'normal' life (ID13). Although budgetary constraints on Trusts and charities delivering specialist palliative care were acknowledged, they result in some not being offered a home death (ID49) and families being left with very little support (ID47). An integrated health service and less reliance on family were recommended:

'I think there is an obligation on the state and an essential part of the health service and that palliative care should be as much part of the health service as any other part as it is too important and too relevant to just depend on the man in the street' (ID42).

\section{Strategies to promote public awareness of palliative care}

Two main themes were identified for enhancing public awareness, which included: dispelling myths and raising awareness of 'palliative care' and the importance of public education.

\section{Dispelling myths and raising awareness of palliative care. It was} acknowledged that cancer, commonly known as the 'big C' (ID15), is feared within our culture and that death is a 'taboo' subject (ID48).

'People are scared. It's not discussed. It's the final taboo' (ID57). 
Long-standing 'stigma' attributed to cancer was generally reinforced with people preferring not to publicly discuss their illness. Assumptions or myths were commonly associated between cancer, palliative care and death.

'Well I think that a lot of people automatically assume palliative care, you are going to be dead in a few days. So I think that myth needs to be dispelled' (ID46, retired health service personnel).

Respondents attributed perceived stigma with preferences not to contemplate death (ID46) and understood that superstitious individuals feared doing so would 'bring death to your door' (ID39). Whilst respecting that 'not everyone's happy talking about death' (ID20), it was suggested that encouraging conversations may enable relatives' wishes to be explored (ID34) and give reassurance that palliative care services are there for the 'necessity and comfort of patients and their families' (ID15).

The importance of public education. Education targeted towards different groups is an important strategy for improving public awareness of palliative care. Respondents suggested the following: TV advertisements or posters/ leaflets; road shows offering a light-hearted approach to illness or death; or inviting cancer survivors to community or church groups as 'those who have gone through it are best placed to educate others' (ID24) and are natural 'ambassadors' (ID10); being more open and honest about different types of cancer may 'take the shroud off the mystery [of] cancer' and highlight that 
'cancer is not an immediate death sentence...or the killer disease that it always was' (ID15); introducing education about death and dying in schools or universities when it is easier to absorb the information, rather than when a relative is diagnosed is diagnosed or dies (ID51); and inviting children to share photos of people who have died (ID5) to normalise illness and death.

At the time of data collection, the Liverpool Care Pathway received negative media attention, which was damaging to palliative and end of life care.

'I think this Liverpool Care Pathway, all the latest stuff in the media, is not doing the cause of palliative care any good. My experience of it from my husband who died last year was fantastic... As it turned out it was a good death... I think my husband was on the care pathway but we actually couldn't have wished for anything better for him...' (ID46).

Changing peoples' attitudes and improving public awareness was recognised as a slow process but ensuring that the 'right people' lead media campaigns, despite economic barriers, would be a start (ID20). Respondents with a better understanding of palliative care advocated for increased public awareness and open communication about dying.

\section{Discussion}

Analysis revealed that participants' knowledge of palliative care was largely influenced by their own personal or professional caring experiences and / or contact with care organisations. There was only limited reference to the media 
as an existing source of knowledge around palliative care, although broad media initiatives were promoted as part of the solution to improving public awareness. There was no widely recognised or agreed focal source of information for palliative care - participants reported that they would seek information from existing contacts (e.g. GP) or via the internet. Participants cited a preference for and expectation that palliative care was provided at home, that care should be holistic in its provision and should provide support for the patient's family. Participants recognised that myths, misunderstandings and anxieties remain in contemporary society around palliative care, death and dying. Broad public and community based educational and media initiatives provided by people with relevant experience were offered as strategies for promoting knowledge and awareness of palliative care.

Findings are a result of in-depth interviews with a relatively large group of interviewees $(\mathrm{N}=40)$. However, the current sample (drawn from a membership scheme established to provide an independent voice for patients, clients, carers and communities on health and social care issues) could be argued to represent an atypical group with views and experiences that are not representative of the broader public - who may in general be less knowledgeable about the role and meaning of palliative care. Some participants had direct experience of palliative care and offered insightful quotes directly related to clinical care. Consequently, rather than providing an estimation of the extent of public knowledge around palliative care, the value of the findings is in highlighting the sources of that knowledge and those strategies which the participants perceive to be valuable in raising awareness 
around these issues. These findings contribute to the existing international evidence whilst has demonstrated that public knowledge of palliative care in many societies is limited and that the public is still death-denying ${ }^{4-11}$. The study has found this to be the case in participants with knowledge of healthcare systems and drawn from a membership scheme and it is therefore likely that outside of this group public knowledge of palliative care is much reduced.

The study findings reinforce existing evidence that individuals with a good understanding of palliative care are more likely to have worked or known someone who has worked in a palliative care setting ${ }^{4}$, or to have a close friend or family member who received palliative care ${ }^{31}$. Hospices, community organisations and schools may therefore have a pivotal role to play in promoting direct contact between the public and those receiving or providing palliative care services. Whilst broad media initiatives may help to raise awareness, these are more likely to be effective if they are delivered by individuals with relevant experience and where they promote direct contact between community groups or schools and palliative care patients or providers - interventions such the St Christopher's Schools Project in the $\mathrm{UK}^{32}$ and population based interventions in Japan ${ }^{33}$ Kellehear's principles of health promoting palliative care ${ }^{31,34-35}$, have long advocated the role of the wider community and the importance of a participatory approach in normalising issues around death and dying, raising knowledge and understanding and reducing public anxieties. Palliative care and public health services should work together to develop health promotion which will benefit 
palliative care and will be effective in changing public knowledge, attitudes and behaviour by combining the paradigms of public health and end of life care. This requires a long term commitment for health promoting palliative care, seeking to discover and maximise transferable skills and experience from public health interventions.

Our findings also reinforce and affirm from a lay perspective, the position taken by the World Health Organisation $(\mathrm{WHO})^{1-2}$ in promoting physical, psychological and spiritual care for the 'whole person' - care which should be delivered by knowledgeable, informed, compassionate and caring practitioners. In addition, participants also reinforced WHO statements ${ }^{36}$ that this holistic care should seek to improve the quality of life families, in addition to patients. Family care giving has been identified as a top international research priority in end of life care ${ }^{37}$ particularly for those caring for people with non-malignant disease..$^{38-39}$

There are implications of these findings for both specialist and non-specialist health professionals, particularly around their contribution to initiatives which promote contact between community groups and schools, and palliative care patients and providers (with relevant and credible experience). Increased communication and knowledge sharing between health care professionals (both general and specialist) may also help to create a common language and definition of palliative care - something which has been historically alusive..$^{10,11}$ 
Future research should seek to assess the effectiveness of public and community based interventions, using methodologies tailored in response to varied cultural and societal community characteristics, and the impact of these interventions on community knowledge, attitudes and behaviours.

\section{Conclusions}

The importance of this study lies in its contribution to contemporary palliative care literature. Knowledge of palliative care is largely gained through experiences of receiving or providing care. Initiatives aiming to increase knowledge and awareness of palliative care should seek to increase contact between communities and those receiving or providing care and should involve individuals with relevant experience.

Word Count: 4017 (including quotes)

\section{Acknowledgments}

The authors thank the Northern Ireland Patient Client Council for their assistance with this project, particularly members of their membership scheme who took part in telephone interviews. 


\section{References}

1. World Health Organization. World Health Report 2002: Reducing Risks, Promoting Healthy Life. WHO, Geneva, 2002.

2. World Health Organisation. Definition of Palliative Care. http://www.who.int/cancer/palliative/definition (accessed 31 ${ }^{\text {st }}$ January 2013).

3. Kellehear A. Health promoting palliative care: developing a social model of practice. Health Promotion Journal of Australia 1999; 9(1): 30-34.

4. Benini F, Fabris M, Pace DS, Verno V, Negro V, De Conno F, and Orzalesi MM. Awareness, understanding and attitudes of Italians regarding palliative care. Annali Dell'Istituto Superiore di Sanita 2011; 47(3): 253-9.

5. Center to Advance Palliative Care. Public Opinion Research on Palliative Care. A Report based on Research by Public Opinion Strategies. Center to Advance Palliative Care, 2011.

6. Claxton-Oldfield S, Claxton-Oldfield J and Rishchynski G. Understanding of the term 'Palliative Care': A Canadian survey. AJHPM, 2004; 21(2):105-110.

7. Hirai K, Kudo T, Akiyama M, Matoba M, Shiozaki M, Yamaki T, Yamagishi A, Miyashita M, Morita T, and Eguchi K. Public awareness, knowledge of availability, and readiness for cancer palliative care services: a populationbased survey across four regions in Japan. Journal of Palliat Med, 2011; 14(8):918-22.

8. IPSOS MORI. Attitudes Towards Death and Dying in the East of England. IPSOS MORI, 2011.

9. Krishbaun MYN, Carey I, Purcell B and Nash S. Talking about Dying and Death: a focus group study to explore a local community perspective. Nursing Reports 2011; 1(e8): 29-34.

10. Scottish Government. Living and Dying Well - A National Action Plan for End of Life Care in Scotland. Scottish Government, 2008. 
http://www.scotland.gov.uk/Publications/2008/10/01091608/0 (accessed 31st January 2013)

11. Seymour J, French J, and Richardson E. Dying matters: let's talk about it. BMJ 2010; 341:c4860.

12. Arends J, Mross K, Pletschen L, and Azemar M. Palliative treatment: anticancer, antisymptom, or end-of-life care? Journal of Clinical Oncology 2011; 29(34):4591.

13. Gysels M, Evans N, Menaca A, Andrew E, Toscani F, Finetti S, Pasman HR, Higginson I, Harding R, and Pool R. Project PRISMA. Culture and end of life care: a scoping exercise in seven European countries. PLOS ONE 2012; 7(4):e34188.

14. Meier DE and Brawley OW. Palliative care and the quality of life. J Clin Oncol 2011; 29(20):2750-2.

15. Bingham S. NHS millions for controversial care pathway. The Telegraph, $31^{\text {st }}$ Oct 2012; http://www.telegraph.co.uk/health/healthnews/9644287/NHS-

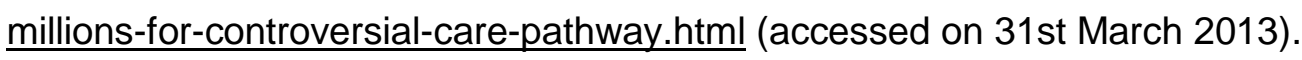

16. Torjesen I. Bad press over Liverpool care pathway has scared patients and doctors, say experts. BMJ 2013; 346: f175.

17. Chinthapalli K. The Liverpool care pathway: what do specialists think? BMJ, 2013; 346:f1184

18. Charlton RC. Attitudes towards care of the dying: a questionnaire survey of general practice attenders. Fam Pract 1991; 8:356-359.

19. Charlton R, Dovey S, Mizushima Y, et al. Attitudes to death and dying in the UK, New Zealand, and Japan. J Palliat Care 1995; 1:42-47.

20. Clarke A and Seymour J (Peer Education Project Group). Opening the Door for Older People to Explore End of Life Issues. London: Help the Aged, 2006. 
21. Cox K, Bird L, Arthur A, Kennedy S, Pollock K, Kumar A, Stanton W and Seymour J. Public attitudes to death and dying in the UK: a review of published literature. BMJ Support Palliat Care; bmjspcare-2012-000203

22. Lloyd-Williams M, Kennedy $\mathrm{V}$, Sixsmith A, et al. The end of life: a qualitative study of the perceptions of people over the age of 80 on issues surrounding death and dying. J Pain Symptom Manage; 2007; 34:60-66.

23. Seymour J, Kennedy S, Arthur A, et al. Public attitudes to death, dying and bereavement: a systematic synthesis. A report to the National Council for Palliative Care and National End of Life Care Programme. Nottingham. University of Nottingham, 2009.

24. McCarthy J, Weafer $\mathrm{J}$ and Loughrey M. Irish views on death and dying: a national survey. J Med Ethics 2010; 36(8):454-458.

25. Norfolk Health Overview and Scrutiny Committee. How we manage death and dying in Norfolk County and Waveney, 2005. www.norfolk.gov.uk/view/NCC091241.

26. Baker ME. Economic, political and ethnic influences on end-of-life decisionmaking: A decade in review. Journal of Health \& Social Policy 2001; 14(3), 27-39.

27. Conner, NE. Predictive factors of hospice use among Blacks: applying Andersen's Behavioral Model. American Journal of Hospice \& Palliative Medicine 2012, 29(5):368-74.

28. Enguidanos S, Kogan AC, Lorenz K, Taylor G. Use of role model stories to overcome barriers to hospice among African Americans. J Palliat Med 2011; 14(2):161-8.

29. Casarett D. Ethical Considerations in End-of-Life Care and Research. J. Palliat Med 2005; 8(1):148-60.

30. Miles MB and AM Huberman. Qualitative Data Analysis: An Expanded Sourcebook. London: Sage Publications Ltd, 1994.. 
31. Kellehear A and O'Connor D. Health promoting palliative care: A practice Example. Critical Public Health 2008; 18(1):111-115.

32. Tsiris T, Tasker M, Lawson V, Prince G, Dives T, Sands M and Ridley A. Music and arts in health promotion and death education: The St Christopher's Schools Project. Music and Arts in Action, 2011; 3(2): 95-119.

33. Sato K, Miyashita M, Morita T and Suzuki M. The long-term effect of a population-based educational intervention focusing on end-of-life home care, life-prolongation treatment, and knowledge about palliative care. Journal of Palliative Care. 2009; 25(3):206-12.

34. Kellehear A. Health promoting palliative care. Melbourne: Oxford University Press, 1999.

35. Kellehear A and Young B. Resilient communities. In: B. Monroe and D. Oliviere, eds. Resilience in palliative care. Oxford: Oxford University Press, 2007.

36. World Health Organisation. The Solid Facts: Palliative Care,. 2004. http://www.euro.who.int/_data/assets/pdf_file/0003/98418/E82931.pdf [accessed 1st March 2013]

37. Hudson PL, Thomas K, Trauer T, Remedios C, et al. Psychological and social profile of family caregivers on commencement of palliative care. J Pain Symptom Manage, 2011; 41(3):522-34.

38. Noble $\mathrm{H}$, Kelly DM and Hudson $\mathrm{P}$. Experiences of carers supporting dying renal patients managed without dialysis. J Adv Nurs, 2013; 10.1111/jan.12049

39. Braithwaite M, Philip J, Tranberg H, Finlayson F, Gold M, Kotsimbos T and Wilson J. End of life care in CF: patients, families and staff experiences and unmet needs. J Cystic Fibrosis, 2011; 10(4): 253-257. 
Table 1: Telephone interview schedule

\section{Introduction}

- Welcome and introduction.

- Screen participant to ensure they meet the inclusion criteria (not under 18 years of age, diagnosed with terminal illness, suffered bereavement within the last 6 months or have not provided written consent.)

- Review of purpose, rules and confirm consent forms have been signed

- Recap on the sensitive nature of the topic to be discussed and remind participants that they can withdraw at any stage.

\section{Topic themes \& questions}

General knowledge of palliative care

- Could you please describe for me what you think palliative care is?

- Where do you think palliative care takes place?

- Views and opinions of palliative care.

Knowledge and information

- If you needed information about palliative care, where would you look for it, or whom would you ask?

\section{Expectations}

- What care would you expect palliative care services to deliver?

\section{Accessibility}

- Where do you think people go to get these services?

\section{Future Strategies}

- What do you think are the supporting factors for promoting public awareness of palliative care?

- What do you think are the inhibiting factors for promoting public awareness of palliative care?

- What could be done to promote more openness in discussion (and to inform future strategies)?

Warm down/ Debrief exercise

Reflect on main issues discussed and remind the participant of confidentiality and information and support services available, final thank you 
Table 2: Participant demographic characteristics

\begin{tabular}{|c|c|}
\hline \multicolumn{2}{|l|}{ Gender \%(n) } \\
\hline Male & $26(13)$ \\
\hline Female & $74(37)$ \\
\hline \multicolumn{2}{|l|}{ Age (years) \%(n) } \\
\hline Under 20 & $0(0)$ \\
\hline $21-29$ & $2(1)$ \\
\hline $30-39$ & $6(3)$ \\
\hline $40-49$ & $10(5)$ \\
\hline $50-59$ & $20(10)$ \\
\hline $60-69$ & $32(16)$ \\
\hline $70-70$ & $28(14)$ \\
\hline 80 and over & $2(1)$ \\
\hline \multicolumn{2}{|l|}{ Employment Status \%(n) } \\
\hline Employed & $22(11)$ \\
\hline Out of work & $8(4)$ \\
\hline Homemaker & $2(1)$ \\
\hline Student & $0(0)$ \\
\hline Retired & $62(31)$ \\
\hline Unable to work & $6(3)$ \\
\hline \multicolumn{2}{|l|}{ Marital Status \% (n) } \\
\hline Single, never married & $8(4)$ \\
\hline Co-habiting & $0(0)$ \\
\hline Married & $62(31)$ \\
\hline
\end{tabular}




\begin{tabular}{|c|c|}
\hline Separated / Divorced & $12(6)$ \\
\hline Widow / Widower & $16(8)$ \\
\hline Civil partnership & $2(1)$ \\
\hline \multicolumn{2}{|l|}{ Religious Preference \% (n) } \\
\hline Christian & $90(45)$ \\
\hline Other & $10(5)$ \\
\hline \multicolumn{2}{|l|}{ Ethnic Origin \% (n) } \\
\hline White & $100(50)$ \\
\hline
\end{tabular}

